\title{
Educação com base na propaganda para o ensino integrado da preservação do meio ambiente
}

Este artigo visa concatenar meio ambiente, reciclagem, publicidade, administração e engenharia, propondo uma aprendizagem nos aspectos conceituais de administração de recursos recicláveis, por meio de imagens e vídeos educacionais, a fim de evitar desperdícios e poluição, bem como criar consciência ecológica através de projetos voltados para a sustentabilidade de modo integrado, dentro da Teoria da Complexidade entre as áreas. Será apresentada uma relação da Teoria da Complexidade, de Edgar Morin, e alguns fundamentos semióticos de Vygotsky e Feuerstein relacionados ao ensino dentro do pensamento lógico e da formação social da mente, abordado pelo primeiro, e a importância do papel do mediador, destacado pelo segundo. Tem-se como ferramenta os conceitos envolvidos pela utilização de signos tanto para a compreensão do mundo, formação das crenças ou comando para as ações.

Palavras-chave: Educação; Semiótica; Teoria da Complexidade.

\section{Advertising-based education for integrated environmental preservation education}

This article aims to concatenate the environment, recycling, advertising, administration and engineering by proposing a learning in the conceptual aspects of managing recyclable resources through educational images and videos to avoid waste and pollution, as well as to create ecological awareness through projects focused on sustainability in an integrated way, within the Complexity Theory between the areas. A relationship between Edgar Morin's Theory of Complexity and some semiotic foundations of Vygotsky and Feuerstein related to teaching within the logical thinking and social formation of the mind, addressed by the former, and the importance of the mediator's role, highlighted by the latter, will be presented. It has as a tool the concepts involved using signs both for understanding the world, forming beliefs or commanding actions.

Keywords: Education; Semiotics; Complexity theory.

Topic: Desenvolvimento, Sustentabilidade e Meio Ambiente

Reviewed anonymously in the process of blind peer.
Received: 08/07/2018

Approved: 15/10/2018

Thais Rocha de Oliveira (1)

Fundação Getúlio Vargas, Brasil

http://lattes.cnpq.br/6821236617748289

http://orcid.org/0000-0003-4381-2044

thaisrocholi.rj@gmail.com

\section{Referencing this:}

OLIVEIRA, T. R.. Educação com base na propaganda para o ensino integrado da preservação do meio ambiente. Natural Resources, v.8, n.2, p.31-37, 2018. DOI: http://doi.org/10.6008/CBPC2237$\underline{9290.2018 .002 .0004}$ 


\section{INTRODUÇÃO}

Neste início de século XXI, as questões ambientais vêm sendo um assunto que vem acompanhado de muitas preocupações devido ao dinamismo econômico. Como consequência, esses assuntos ganham destaque nas mídias. Considera-se relevante que se tenha um olhar crítico da educação para que as próximas gerações não reproduzam os mesmos comportamentos sem tomar para si as responsabilidades. É urgente que se criem discussões abordando problemas socioambientais, para além do senso comum, através do conhecimento de mundo integrado ao ambiente escolar.

Para melhor explicar esta preocupação, será proposta uma integração entre as áreas do campo do saber da engenharia com o meio ambiente, administração de recursos renováveis, reciclagem, publicidade e semiótica, a fim de contribuir para um ensino integrado entre as áreas. A preocupação deste artigo remete a necessidade de promover uma educação capaz de lidar com situações em transformação presentes na realidade dos indivíduos. Dentro desta perspectiva, propõe-se que a emergência do saber ambiental abre um novo horizonte para a sociologia do saber científico. Levando em consideração que o meio ambiente não partiu de uma ação ou de um feito humano, porém, com tantas intervenções humanas e desmatamento, o indivíduo torna-se responsável por reparar e preservar os ecossistemas.

Diante do exposto, faz-se necessário pensar em alternativas e estratégias didáticas para levar discussões sobre a engenharia e sua relação com o meio ambiente, a administração, reciclagem, tendo como aparato a publicidade e semióticas nas salas de aula dos cursos universitários, bem como a necessidade da organização de ferramentas e modelos de ensino que promovam atividades teoricamente mais práticas em turmas, de modo a se tornar viável e urgente nos projetos de construção civil. O instrumento proposto para atingir esse objetivo é o estudo das ideias conceituais da administração de recursos naturais, baseada em estratégias de produção sustentáveis, abordando o tema de fatores de produção (terra, trabalho e capital), estabelecendo uma correspondência entre causa e efeito.

\section{REVISÃO TEÓRICA}

\section{Formação de conceitos integrados face ao meio ambiente com base na propaganda}

Com o desenvolvimento da ciência, acumula-se conhecimento, cujo acervo da humanidade abrange o conteúdo das áreas científicas. As pesquisas ficam disponíveis conforme a proporção dos interesses sociais cresce em relação aos saberes culturais e usos tecnológicos. De acordo com Hume (1989), não é difícil aparecerem ideias independentes de impressões parecidas. "É evidente que existe um princípio de conexão entre os diferentes pensamentos ou ideias da mente e que, no seu aparecimento à memória ou à imaginação, se apresentam umas às outras com um certo grau de método e regularidade" (HUME, 1989).

Em algumas situações, as questões sociais são colocadas em harmonia com o conhecimento sistematizado e descentralizado, fomentando um ambiente adequado ao nascimento de uma ideia, ou à realização de uma invenção, ou também à divulgação de um processo, projeto ou sonho. Conforme o filósofo francês Edgar Morin, o debate sobre assuntos relacionados à crise planetária tem circundado todos os seus estudos, cuja situação denominou de policrise. Esta agonia planetária se agravou dado ao sentimento de 
impotência diante de problemas vindouros. Assim, uma das formas de se contornar tais problemáticas é a educação visando edificar a partir das ruínas.

A educação, que é complexa por essência, influi e é influenciada pelas partes e aspectos que a define e constitui [...] é urgente repensá-la a partir de uma visão totalizadora que a torne envolvida com as partes e os recortes, mas sempre em função das partes e de um todo uno, múltiplo e complexo, simultaneamente. Ao se pensar na educação dentro da complexidade, cremos que ela deve ser um processo que cause influência positiva na formação do sujeito cidadão. Para tal fim, a autoformação deve vincular-se à educação, cooperando na constituição do sujeito complexo que é atravessado pelas múltiplas dimensões, seja no âmbito político, econômico, cultural, mitológico, religioso, ambiental, e, sobretudo, pela biodiversidade dimensional.

No entanto, ao se refletir acerca dos modelos futurológicos logo temos como resultado as catástrofes, uma vez que se tornam escassos os recursos naturais não-renováveis, cujo problema é peça central. Assim, quando se pensa nos recursos da terra como sendo finitos, devemos buscar condições econômico-tecnológicas disponíveis para reinventar. 'Impacto ambiental' está baseado na perspectiva globalizante, onde o ambiente é o meio de vida, além de fornecer recursos naturais (SÁNCHEZ, 2006). Cabe refletir sobre o conceito de que, sendo a terra finita, seus recursos também são. Assim, ver-se como possibilidade a criação de processos de reciclagem de todas as matérias-primas minerais, onde se busca a criação de edificações sustentáveis como meios de preservação do meio ambiente. Empreendimentos sustentáveis são bastante vantajosos quanto aos seus benefícios sociais, ambientais e econômicos.

Os benefícios sociais abrangem a geração de emprego e renda. Os benefícios ambientais podem ser vistos quando os empreendimentos sustentáveis são concebidos e planejados suprimindo menores áreas de vegetação, otimizando o uso de materiais, gerando menos emissões de resíduos durante sua fase de construção, além de demandar menos energia e água nas fases de operação, podem ser reaproveitados e reciclados ao final do ciclo de vida. Os benefícios econômicos aparecem no aumento da eficiência no uso de recursos financeiros na construção, a oferta de um retorno financeiro justo aos empreendedores e acionistas, na indução de aumento da produtividade de trabalhadores por encontrarem-se em um ambiente saudável e confortável.

A construção de conceitos com vista à racionalidade ambiental requer mudanças de opiniões e métodos das ciências e das áreas do campo do saber, de valores e de crenças sociais. Como apontado por Carvalho (2001), a educação ambiental é um processo que demanda mudanças na sua identidade, bem como a adoção de uma nova postura diante do mundo. Estas transformações ideológicas e epistêmicas não estão associadas aos tipos de classes sociais, mas partem da análise de processos complexos que estão em concorrência com os interesses de diferentes grupos de poder no que se refere à apropriação dos recursos naturais, interesses institucionais de uma administração pública setorializada e interesses disciplinares ligados à área que se identifica e se procura estudar dentro das universidades.

Também se sabe dos efeitos potenciais que podem gerar uma propaganda. Portanto, ver-se como um apoio nas aulas, os recursos de vídeos curtos de 2 minutos produzidos por alunos do curso de publicidade 
direcionados a educação ambiental, criando expectativas positivas e interesse dos demais do curso de engenharia para os assuntos do planejamento de construções sustentáveis, com isso espera-se ideias alternativas para novos projetos. "Televisão e vídeo partem do concreto, do visível, do imediato, do próximo - daquilo que toca os sentidos. Estão ao nosso alcance através dos recortes visuais, do close, do som estéreo envolvente" (MORAN et al., 2000).

Moran (2000) ressalta que pode ser comprovado que o ver e o visualizar, a observação das situações diante de si, bem como as pessoas, os cenários, as cores, as relações espaciais, apresentam um ver entrecortado - com múltiplos recortes da realidade - por meio dos planos, e muitos ritmos visuais: imagens estáticas e dinâmicas, câmera fixa ou em movimento, uma ou várias câmeras, personagens quietos ou movendo-se, imagens ao vivo, gravadas ou criadas no computador [...] são sensoriais, visuais, linguagem falada, linguagem musical e escrita.

Linguagens que interagem superpostas, interligadas, somadas, não separadas. Daí sua força, atingem por todos os sentidos e de todas as maneiras. Televisão e vídeo formam um elo entre a comunicação sensorial-cinestésica, com audiovisual, a intuição lógica, a emoção com a razão. Integração que começa pelo sensorial, pelo emocional e pelo intuitivo, para atingir posteriormente o racional (MORAN et al., 2000).

\section{O Inconsciente na Propaganda}

As pesquisas do médico neurologista Sigmund Freud acerca da psique humana, à luz da psicanálise, surgiram como um marco na história da psicologia. Seus estudos acerca do inconsciente humano, ainda em pleno século XXI, confundem os estudiosos da área. Proveniente da psicoterapia, a psicanálise estuda a atividade mental com base na crença de um inconsciente humano que atua como 'pano de fundo' nas atividades humanas conscientes. "[...] De acordo com a teoria psicanalítica, os processos mentais inconscientes são de grande frequência e significado no funcionamento mental normal, bem como no anormal" (BRENNER, 1987).

Portanto, a psicologia de massa trata o ser individual como membro de uma tribo, um povo, uma casta, uma classe, uma instituição, ou como parte de uma aglomeração que se organiza como massa em determinado momento, para um certo fim (FREUD, 2011). Conforme os efeitos do grupo no indivíduo, bem como a transformação nele causada, Freud ressalta que as particularidades individuais são apagadas enquanto em grupo, nasce a homogeneidade entre os integrantes. Freud relata que apenas as características iguais ficam expostas. No entanto, é dentro desta perspectiva que se sugere uma metodologia focada em recursos do dia a dia, como indução através de mídias sociais e vídeos para educação ambiental.

\section{METODOLOGIA}

Este estudo se desenvolve através de uma abordagem qualitativa, utilizando-se do procedimento de pesquisa bibliográfica valendo-se da técnica de análise de conteúdo. O processo de seleção de artigos relevantes sobre os temas publicados entre os anos de 2010 e de 2017, compõe o cerne para o referencial bibliográfico sobre as temáticas: meio ambiente, sustentabilidade, semiótica e a teoria da complexidade. A 
base de dados consultada compreende a Scientific Eletronic Libraly Online (Scielo). Filtrando os artigos, escolheram-se os pertencentes às áreas temáticas de Sociologia, Educação e Gestão.

Ao se analisar a construção de uma proposta pedagógica de um curso de engenharia civil com pressupostos de sustentabilidade com apoio da propaganda, teve-se como base a interdisciplinaridade contida na visão de Morin (2001), que se torna viável o desenvolvimento das habilidades e capacidades a partir dos valores da sustentabilidade.

A origem da palavra Educação (e-duc-a-ação) provém do lexema duc, constituinte da palavra latina ducere, com o sentido de levar, conduzir, puxar, liderar para a frente (HECKLER et al., 1984a). Curiosamente, são da mesma família as palavras: condução, produção, reprodução e sedução, assim como dedução, indução e abdução (ou retrodução), sendo essas três últimas referentes às principais operações lógicas estudadas por Peirce. O termo ensino (en-sin-o), por sua vez, advém do latim signum, marca distintiva, sinal (HECKLER et al., 1984b), donde derivam também signo, desenho, desígnio, senha, significação, sina, sino etc., ou seja, é uma família numerosa. Pode-se ainda levar esta família à origem de secare, cortar (fazer sinais por incisão). Estudar, por sua vez, deriva do latim studere, ser zeloso, guardar com cuidado (HECKLER et al., 1984b).

A formação de engenheiros civis com pressupostos em sustentabilidade deve privilegiar novas propostas pedagógicas interdisciplinares, em que a visão integrada, sistêmica e holística substitua os projetos pedagógicos disciplinares dentro da inércia de uma realidade fragmentada. Bezerra et al. (2007) salientam a necessidade de se trabalhar questões ambientais primeiramente com professores para sensibilizá-los quanto a serem partes integrantes nas questões ambientais a fim de torná-los multiplicadores dentro da sala de aula.

Para isso, tem-se como um meio, a propaganda utilizada como uma metodologia relacionada com alguns pensadores aqui discutidos. Conforme conceitua Santaella (2010), as linguagens estão no mundo e nós estamos na linguagem. A Semiótica é a ciência que visa investigar todas as linguagens possíveis, ou seja, tem por objetivo o exame dos modos de constituição de todo e qualquer fenômeno como fenômeno de produção de significação e de sentido.

Ao lado dos fenômenos naturais, do material tecnológico e dos artigos de consumo, existe um universo em particular, o universo de signos. Ali onde o signo se encontra, encontra-se também o ideológico. Tudo que é ideológico possui um valor semiótico (BAKHTIN, 2010). Conforme Vygotsky, a análise da esfera dos processos recria a percepção (seleção, disposição, percepção categorial e classificação elaboradora) e a capacidade de dedução, a qual já estaria totalmente formada aos quatorze anos do indivíduo (VYGOTSKY, 1996). Assim, compreende-se que as funções psíquicas superiores abrangem as operações intelectuais básicas, o pensamento lógico-formal, a capacidade de efetuar operações lógicas atreladas aos conceitos, deste modo o resultado torna possível a realização de nexos e relações lógicas, formando novas capacidades cerebrais.

"Cada conceito aparece ligado a todos os outros [...] a linguagem não é o meio para expressar uma ideia já formada, senão para criá-la, não é o reflexo de uma concepção de mundo já estruturada, senão a atividade que a forma" (VYGOTSKY, 1996). Todo pensamento está vinculado à relação entre os fenômenos da realidade inerentemente representados na consciência. Uma das formas de se fazer um estudo concreto 
do pensamento é o desenvolvimento do próprio conceito, melhor dizendo, é a expansão do significado da palavra. A maneira como se desenvolve o pensamento pode ser considerado como um processo interno e profundo na mudança da estrutura do próprio significado da palavra (VYGOTSKY, 2010). "Todos os conceitos que a criança adquire durante a aprendizagem ela os tomou de empréstimo dos adultos" (VYGOTSKY, 2010).

No entanto, como um molde dá corpo a uma substância, as palavras têm a capacidade de moldar uma atividade dentro de uma determinada estrutura (VYGOTSKY, 2007). Quando o indivíduo está na fase de desenvolvimento da linguagem, utiliza sons que se traduzem em palavras (SOUZA, 2008). Um processo interpessoal se transforma num processo intrapessoal. Todas as funções que principiam o desenvolvimento de uma pessoa surgem duas vezes: primeiro, no nível social, e, depois, no nível individual. As funções superiores se originam das relações reais entre os indivíduos. A internalização das atividades socialmente enraizadas e historicamente desenvolvidas formam o aspecto característico da psicologia humana (VYGOTSKY, 2007).

Quando pensamos, temos presente na consciência ou sensação, imagem ou concepção ou outra representação - como um signo. Dentro desta lógica, um signo possui três referências: primeiro, é signo para algum pensamento que o interpreta; segundo, é signo para algum objeto que se the equivale nesse pensamento; terceiro, é signo sob algum aspecto ou qualidade que o liga ao seu objeto (PEIRCE, 1980). Para Feuerstein, um conjunto formado de enunciados gera um argumento, cuja combinação de enunciados iniciais provocam uma conclusão (GOMES, 2002).

Ao se analisar os filósofos aqui pesquisados, Feuerstein foi o que mais teve progresso nos estudos teóricos a aplicações práticas da lógica na aprendizagem. Sua abordagem dá ênfase à necessidade do mediador no processo de aprendizagem, o professor, que irá selecionar, filtrar, organizar, nomear e dar significados ao mundo dos objetos. Feuerstein entende que o raciocínio lógico cria relações entre os objetos e os fenômenos da realidade através da dedução e indução, que são operações lógicas. Raciocinar em nível lógico ultrapassa as fronteiras das impressões imediatas, elucidando relações não visíveis diretamente. 0 pensamento hipotético é um aspecto do processo lógico, envolve a probabilidade um factível acontecimento e indícios retirados da realidade imediata. A formulação de hipóteses abre um leque cognitivo possibilitando previsões e predições probabilísticas (GOMES, 2002).

A lógica é a base do conhecimento humano, pois está na essência das operações cognitivas, em especial a linguagem. É também considerada essencial para educação voltada ao meio ambiente, lançandose mão de dedução, indução e abdução criando uma conexão de influências positivas para melhora da integração entre as áreas com vistas à sustentabilidade.

\section{CONSIDERAÇÕES FINAIS}

A integração da Educação Ambiental, em todos os níveis de educação, sobretudo partindose das iniciativas de construir ideias práticas sustentáveis, é resultado da urgência e do forte apelo emotivo e vital para a sobrevivência humana. Portanto, a racionalidade ambiental no meio acadêmico busca reparar as necessidades ambientais de uma demanda mundial com respeito às 
necessidades básicas, visando retardar a apropriação dos recursos naturais em consumo rápido, contribuindo para uma perspectiva democratizante, inteligente e harmoniosa do fazer científico integrando as áreas.

No mundo acadêmico, a interdisciplinaridade é assunto de discussões desde os anos 1960, sobretudo na Europa. No Brasil, a partir de 1986, ela vem recebendo cada vez mais atenção, embora o projeto baseado na teoria da complexidade entre as áreas esteja no início de um envolvimento responsável com o meio ambiente ainda devagar. Algumas agências governamentais, como a CAPES, MCT, MEC, CNPq, têm percebido a real necessidade e procurado dar apoio e incentivo às suas iniciativas.

A habilidade de se enxergar as coisas positivas das outras disciplinas e incorporar no seu campo de pesquisa e conhecimento é muito enriquecedor, uma vez que se lança mão das questões do desenvolvimento fundamentado em outros métodos e pontos de vista, onde se procura construir soluções para determinados problemas. O estudo dessas relações interconectadas com a propaganda torna o professor muito mais apto ao ensino, cuja disciplina não se torna maçante e sem significado.

\section{REFERÊNCIAS}

BAKHTIN, M.. Marxismo e filosofia da linguagem. 14 ed. São Paulo: Hucitec, 2010

BEZERRA, T. M. O.; GONÇALVES, A. A. C.. Concepções de meio ambiente e educação ambiental por professores da Escola Agrotécnica Federal de Vitória de Santo Antão (PE). Biotemas, p.115-125, 2007

BRENNER, C.. Noções Básicas de Psicanálise. Rio de Janeiro: Imago, 1987.

CARVALHO, I. C. M.. Qual educação ambiental? Elementos para debate sobre educação ambiental e extensão rural. Agroecologia e Desenvolvimento Rural Sustentável, p.5-36, 2001.

FREUD, S.. Psicologia das massas e análise do eu e outros textos (1920-1923). São Paulo: Companhia das Letras, 2011.

GOMES, C. M. A.. Feuerstein e a construção mediada do conhecimento. Porto Alegre: Artmed, 2002.

HECKLER, E.; BACK, S.; MASSING, E. R.. Dicionário morfológico da língua portuguesa. 2 ed. São Leopoldo: Unisinos, 1984a.
HECKLER, E.; BACK, S.; MASSING, E. R.. Dicionário morfológico da língua portuguesa. 4 ed. São Leopoldo: Unisinos, 1984b.

HUME, D.. Investigação sobre o entendimento humano. Lisboa: Edições 70, 1989.

MORAN, J. M.; MASSETTOMORAN, J. M.; MASETTO, M. T.; BEHRENS, M. A.. Novas tecnologias e mediação pedagógica. 3 ed. Campinas: Papirus, 2001.

PEIRCE, C. S.. Escritos coligidos. São Paulo: Abril Cultural, 1980.

PETRAGLIA, I. C.. Edgar Morin: a educação e a complexidade do ser e do saber. 6 ed. Petrópolis: Vozes, 1995.

SÁNCHEZ, L. E.. Avaliação de impacto ambiental: conceitos e métodos. São Paulo: Oficina de Textos, 2006.

SANTAELLA, L.. O que é semiótica?. Brasília: Brasiliense, 2010.

VIGOTSKI, L. S.. A formação social da mente: o desenvolvimento dos processos psicológicos superiores. São Paulo: Martins Fontes, 2007.

A CBPC - Companhia Brasileira de Produção Científica (CNPJ: 11.221.422/0001-03) detém os direitos materiais desta publicação. Os direitos referem-se à publicação do trabalho em qualquer parte do mundo, incluindo os direitos às renovações, expansões e disseminações da contribuição, bem como outros direitos subsidiários. Todos os trabalhos publicados eletronicamente poderão posteriormente ser publicados em coletâneas impressas sob coordenação da Sustenere Publishing, da Companhia Brasileira de Produção Científica e seus parceiros autorizados. Os (as) autores (as) preservam os direitos autorais, mas não têm permissão para a publicação da contribuição em outro meio, impresso ou digital, em português ou em tradução. 